\title{
Première partie - Le mileu et les sources / \\ Présentation
}

Maurice Wolkowitsch

\section{OpenEdition}

\section{Journals}

Édition électronique

URL : https://journals.openedition.org/rhcf/1434

DOI : 10.4000/rhcf.1434

\section{Éditeur}

Rails \& histoire

\section{Édition imprimée}

Date de publication : 10 février 2004

Pagination : 23

ISBN : 0996-9403

ISSN : 0996-9403

\section{Référence électronique}

Maurice Wolkowitsch, «Première partie - Le mileu et les sources / Présentation », Revue d'histoire des chemins de fer [En ligne], 30 | 2004, mis en ligne le 31 août 2012, consulté le 22 avril 2022. URL : http:// journals.openedition.org/rhcf/1434; DOI : https://doi.org/10.4000/rhcf.1434

Ce document a été généré automatiquement le 22 avril 2022

Tous droits réservés 


\title{
Première partie - Le mileu et les sources / Présentation
}

\author{
Maurice Wolkowitsch
}

1 Une première approche consiste à définir le cadre dans lequel les réseaux de chemins de fer secondaires naissent, puis se développent. Ce cadre est complexe, alliant des données administratives, démographiques, juridiques, économiques, sociologiques. Le département étant le territoire dans lequel se développe un réseau, chacun d'entre eux apparaît avec ses spécificités. Le milieu naturel est un facteur dont les effets sont indirects; à l'époque de la construction des lignes secondaires, les hommes disposent des techniques leur permettant de s'affranchir des obstacles naturels : un département de montagne comme l'Isère est bien doté, tandis que d'autres départements montagneux sont sous-équipés ; leur situation est liée non aux accidents du relief, mais à l'économie peu active qui y règne, ne dégageant pas les moyens financiers nécessaires à la réalisation de chemins de fer.

2 Le cadre étant défini, un regard sur les sources disponibles pour étudier les chemins de fer secondaires est nécessaire. À la multiplicité des acteurs et des situations correspond la diversité des sources qui permettent d'approcher la réalité.

\section{INDEX}

Mots-clés : aménagement du territoire, chemin de fer, exploitation ferroviaire, France, infrastructure ferroviaire, politique des transports/France, chemin de fer secondaire 
AUTEUR

MAURICE WOLKOWITSCH

Professeur émérite à l'université de la Méditerranée 